\title{
Effect of Sintering Temperature on Density and Tensile Properties of Titanium Compacts by Metal Injection Molding
}

\author{
Kiyotaká Kato \\ National Industrial Research Institute of Nagoya, 1-1 Hirate-cho Kita-ku, Nagoya 462-8510.
}

Received April 9, 1999

\begin{abstract}
SYNOPSIS
The preparation of pure-Ti compacts by metal injection molding (MIM) process was described in this paper. To reduce contamination at sintering process, the sintering was performed at low temperature range from $1198 \mathrm{~K}$ to $1348 \mathrm{~K}$. On this sintering condition, the properties of sintered compacts were investigated.

When HDH powder (average particle size is $23 \mu \mathrm{m}$ ) was used as the material, the compacts sintered at more than $1298 \mathrm{~K}$ had high tensile strength (630MPa<) in spite of low density $(92.5-94.5 \%)$. When gas-atomized powder (average particle size is $15 \mu \mathrm{m}$ ) was used, the sintered compact had high density ( $95 \%)$ and high elongation (15 20\%) at low sintering temperature range $(1248 \mathrm{~K} \sim 1298 \mathrm{~K})$.

KEY WORDS

metal injection molding, pure-Ti, sintering temperature, density, tensile properties
\end{abstract}

\section{Introduction}

Ti-based alloys have excellent characteristics such as low density, high strength, high corrosion resistance and high biocompatibility. However, in the respect of fabricating compricated shaped parts, low machinalility may be a barrir to practical uses. Therefore, it is considered to be very available that metal injection molding (MIM) process is applied to fabrication of Ti-based alloys parts.

When MIM process is applied to Ti-based alloy, contamination by interstitiallight elements such as oxygen and carbon is serious problem because they have much influence on the mechnical properties of Ti-based alloys ${ }^{1-3}$. Therefore, it is necessary that debinding and sintering conditions are controlled strictly.

In this study, preparing of pure-Ti compacts are performed by MIM process. To reduce contamination at sintering process, the debound compacts are sintered at low temperature less than $1373 \mathrm{~K}$. On this sintering condition, the properties of sintered compacts such as density, tensile strength are mainly investigated.

\section{Experimental Procedure}

Two types pure-Ti powders made from HDH and gasatomization processes were used in this study. The chemical composition and mean particle size of both powders are shown in table 1. The mean particle sizes of $\mathrm{HDH}$ and gas-atomized powder were $24.1 \mu \mathrm{m}$ and $15.2 \mu \mathrm{m}$, respectively. Both powders hardly contain carbon,nitrogen and hydrogen, while contain substantial amount of oxygen. Fig. 2 shows the SEM images of both powders. From these photographs, it was clarified that the $\mathrm{HDH}$ and gas-atomized powders had irregular and spherical shape, respectively.

These powders were mixed with organic binder consisting of wax and resin for about an hour at 383K $393 \mathrm{~K}$ by a planetary rotation type kneading machine. The content ratio of organic binder to powder was $43.1 \mathrm{vol} \%$ for $\mathrm{HDH}$ powder and 33.3 vol\% for gas-atomized powder, corresponding to the shape of powders.

The compounds obtained were injection-molded into the die of tensile test-piece $(110 \mathrm{~mm}(1) \times 7.5 \mathrm{~mm}(\mathrm{w}) \times 4 \mathrm{~mm}(\mathrm{t}))$ using screw type injection molding machine.

Thermal debinding was performed to $648 \mathrm{~K}$ in vacuum $\left(\sim 10^{2} \mathrm{~Pa}\right)$ atmosphere with Ar-gas current. The debinding speed is $1.4 \times 10^{-3} \mathrm{~K} / \mathrm{sec}$ between $423 \mathrm{~K}$ to $573 \mathrm{~K}$. The binder removal ratios of the specimens of both powders were about $90 \%$ on this debinding condition. Then, they were sintered in vacuum $\left(10^{-2} \mathrm{~Pa}\right.$ order $)$ at various temperatures from $1198 \mathrm{~K}$ to $1348 \mathrm{~K}$. The heating rate and holding time were $5.56 \times 10^{-2} \mathrm{~K} / \mathrm{sec}$ and $7.2 \mathrm{ksec}$, respectively.

Fig. 2 shows the schmatic illustration of sintering the specimens in this study. Both heater and vessel of vacuum furnace were made from graphite. The specimens were set 
in alumina $\left(\mathrm{Al}_{2} \mathrm{O}_{3}\right)$ vessel and embedded in alumina powder. Fig. 3 shows the X-ray diffraction patterns of surface of sintered compacts both embedded in alumina powder and put on alumina powder during sintering. The TiC peaks were detected remarkably as well as Ti peaks on the surface of sintered compact put on alumina powder. As this result, the surface became black on this sintering condition. This fact shows that the surface are carbonized by extricated carbon from graphite heater and vessel. By embedding in

Table 1 Chemical compositions and mean particle sizes of $\mathrm{Ti}$ powders.

\begin{tabular}{|c|c|c|c|c|c|}
\hline & \multicolumn{4}{|c|}{ Chemical Comp.(mass\%) } & \multirow{2}{*}{$\begin{array}{c}\text { Mean } \\
\text { particle } \\
\text { size }\end{array}$} \\
\hline & 0 & c & N & H & \\
\hline $\begin{array}{l}\text { HDH } \\
\text { powder }\end{array}$ & 0.23 & 0.01 & 0.01 & 0.06 & $\begin{array}{l}24.1 \mu \mathrm{m} \\
(45 \mu \mathrm{m}>)\end{array}$ \\
\hline $\begin{array}{c}\text { Gas-atomized } \\
\text { powder }\end{array}$ & 0.17 & 0.01 & 0.01 & 0.02 & $\begin{array}{l}15.2 \mu \mathrm{m} \\
(25 \mu \mathrm{m}>)\end{array}$ \\
\hline
\end{tabular}
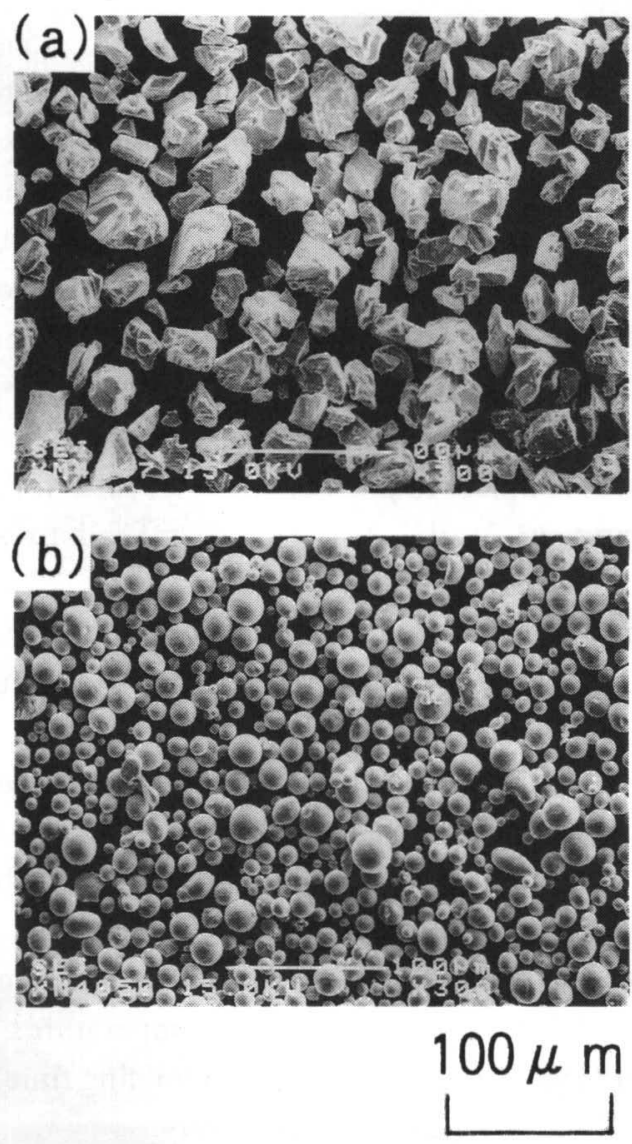

Fig.1 SEM images of Ti powders. (a) HDH powder (b) Gasatomized powder alumina powder, carbonization on the surface are almost prevented.

\section{Results and discussins}

Fig.4 shows the relationship between relative density and sintering temperature in the specimens of both powders. The densities were measured by the underwater gravimetric method, then they were converted into relative valuesby theoretical density of titanium $\left(4.51 \mathrm{Mg} / \mathrm{m}^{3}\right)$. The density of $\mathrm{HDH}$ powder specimen was low value of $82.4 \%$ at $1198 \mathrm{~K}$. However, it rapidly inceased with increasing sintering temperature, and reached to $94.5 \%$ at $1348 \mathrm{~K}$. On the other hand, gas-atomized powder specimen had comparatively high density at low sintering temperature

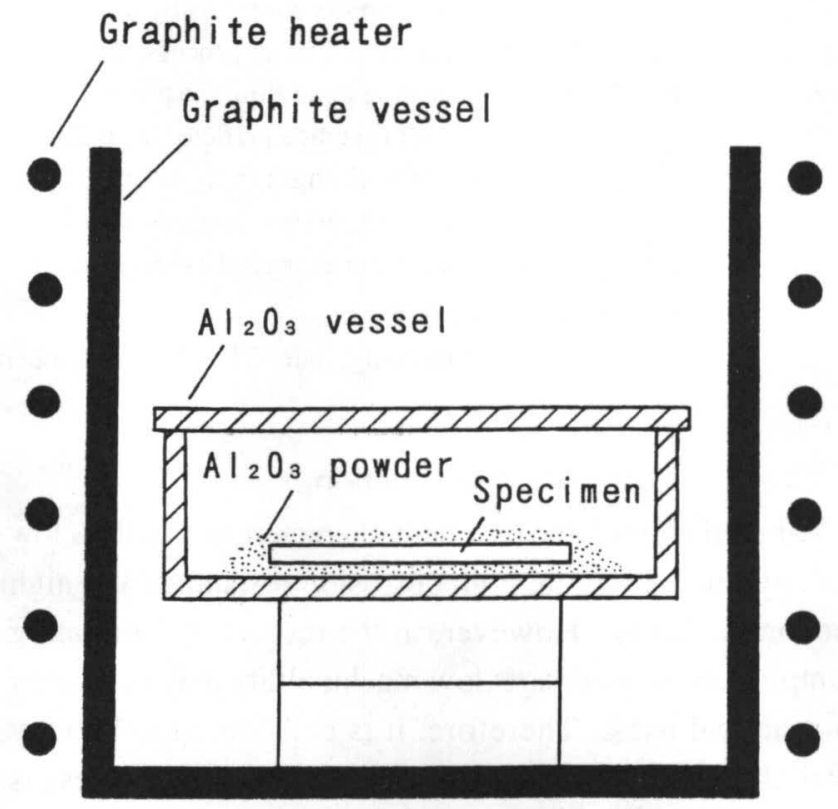

Fig.2 Schmatic illustration of sintering.

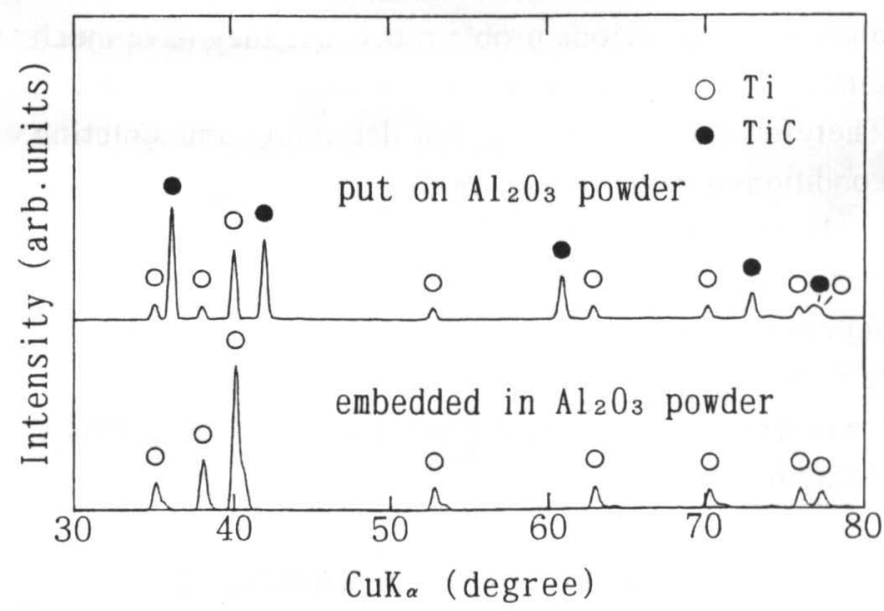

Fig.3 X-ray diffraction patterns of the surface of two sintered specimens; one embedded in alumina powder and one put on alumina powder during sintering. 
such as $92.4 \%$ at $1198 \mathrm{~K}$ and $94.8 \%$ at $1248 \mathrm{~K}$. Gasatomized powder is finer than $\mathrm{HDH}$ powder. Moreover, powder loading of gas-atomized green compact is higher than that of $\mathrm{HDH}$ green compact. These are considered to be the reasons that the gas-atomized powder specimen had higher density than the HDH powder specimen after sintering. However, the increasing rate in density was small more than about $1248 \mathrm{~K}$ in case of the gas-atomized powde specimen. The relative density was $95.8 \%$ at $1348 \mathrm{~K}$ finally.

Fig. 5 shows the relationship between tensile properties in the specimens of both powders at room temperature and sintering temperature. The strain rate in tensile test is $7.0 \times$ $10^{-4}(/ \mathrm{sec})$. The tensile strength of the gas-atomized powder specimen increased slowly with increasing sintering temperature. The difference in strength between the compacts sintered at $1198 \mathrm{~K}$ and $1348 \mathrm{~K}$ was only $60 \mathrm{MPa}$. On the other hand, the $\mathrm{HDH}$ powder specimen showed rapid increase with increasing sintering temperature. The difference in strength between the compacts sintered at $1198 \mathrm{~K}$ and $1348 \mathrm{~K}$ was $210 \mathrm{MPa}$. These tendencies are considered to reflect the changes of density in Fig.3. Especialy, it is worthy of remark that the HDH powder specimen has higher strength than the gas-atomized powder specimen above $1298 \mathrm{~K}$ in spite of its low density.

The behaviour of $0.2 \%$ proof stress of the specimens of both powders showed similar to that of tensile strength. The stress of the HDH powder specimen was higher than that of the gas-atomized powder specimen when sintering temperature was more than $1248 \mathrm{~K}$.

The behaviour of elongation (plastic elongation) in the specimens of both powders show quite different from that of tensile strength and $0.2 \%$ proof stress. The gas-atomized powder specimen showed high elongation of $15 \sim 20 \%$ when

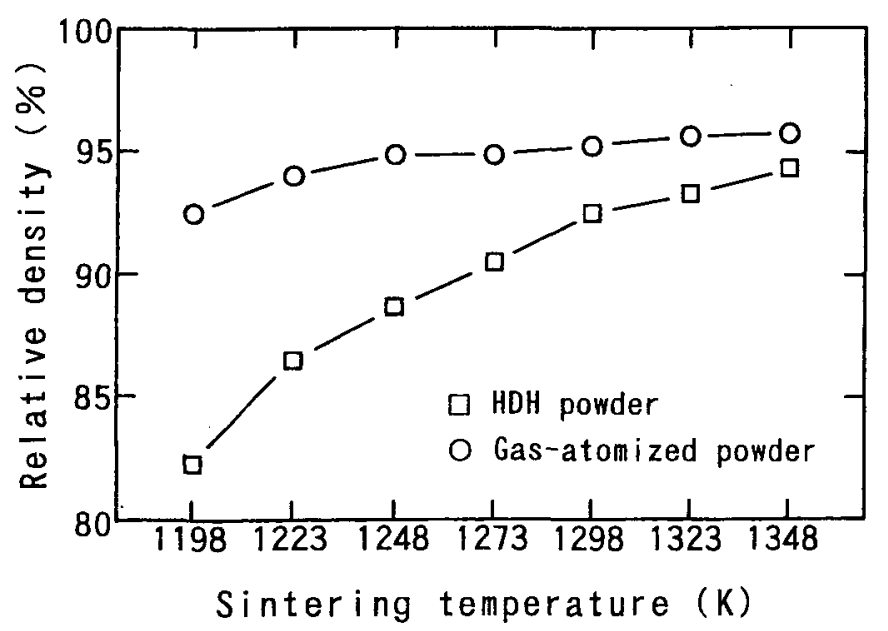

Fig.4 Relationship between relative density and sintering temperature. sintering temperature was from $1223 \mathrm{~K}$ to $1298 \mathrm{~K}$. However, the elongation went down abruptly to about $5 \%$ when sintering temperature was more than $1323 \mathrm{~K}$.

The HDH powder specimen did not had much variation with the change of sitering temperature compared with the gas-atomized powder specimen. As a whole, the elongation of the $\mathrm{HDH}$ powder specimen was lower than that of the gas-atomized powder specimen. The elongation of the $\mathrm{HDH}$ powder specimen was comparatively high value from 6 to $7 \%$ at the sintering temperature of $1273 \mathrm{~K}$ and $1298 \mathrm{~K}$.

As mentioned at introduction, it is the problem that the specimen was contaminated by oxygen and carbon at MIM process. The results of chamical analysis of the sintered

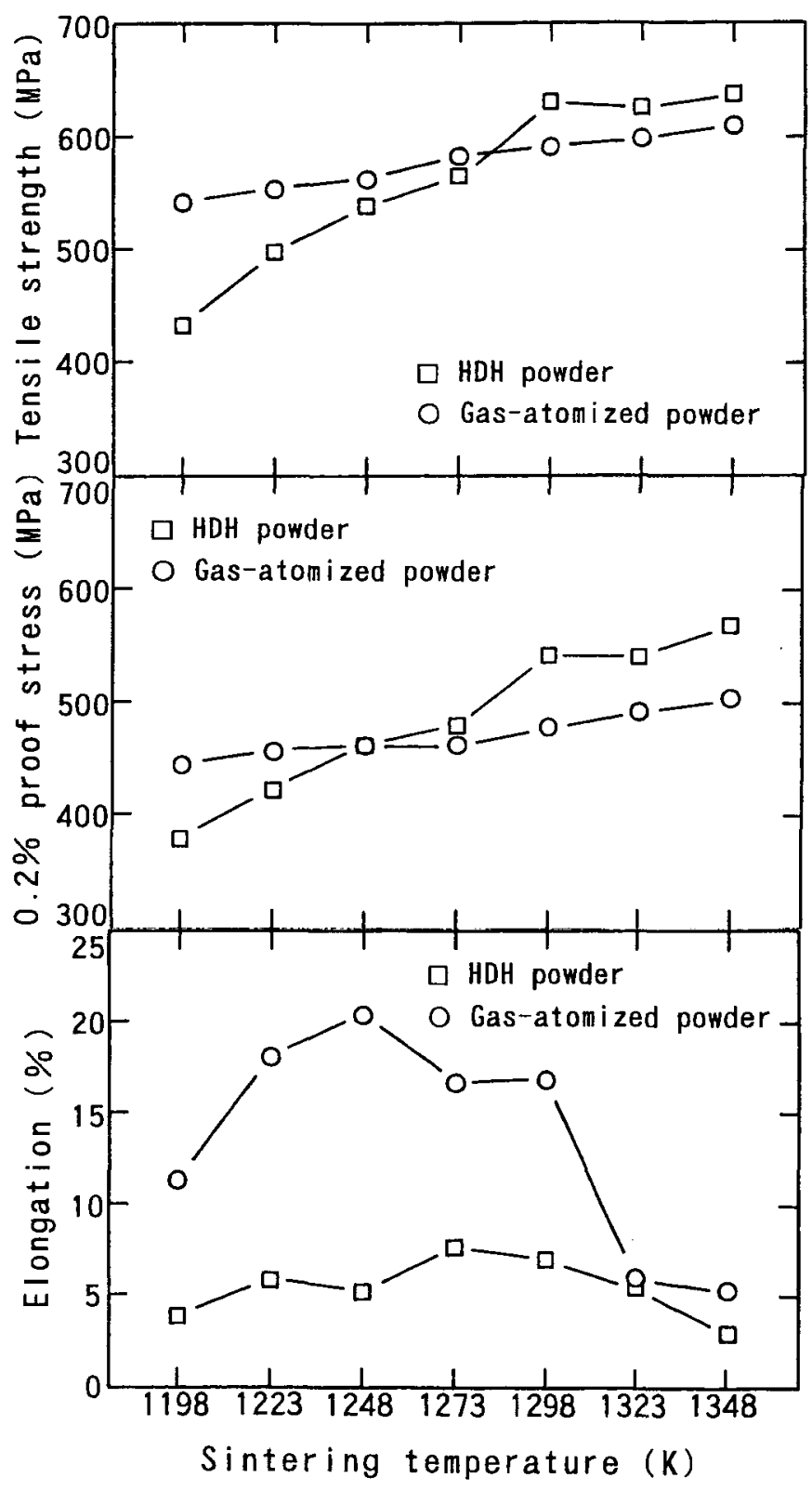

Fig.5 Relationship between tensile properties at room temperature and sintering temperature. 
specimens are shown in Fig.6. The carbon contents of $\mathrm{HDH}$ and gas-atomized powder specimens were about 0.06 0.07 mass $\%$ and $0.05 \sim 0.06$ mass\%, respectively. These values were a little more than those of original powder $(0.01$ mass\%), but they were hardly affected by the sintering temperature. The increase in carbon content hardly influence on the mechnical properties of sintered specimen $^{1,2)}$.

On the other hand, the oxygen content in the specimens of both powders increased substantially from that of original powder. The $\mathrm{HDH}$ powder specimens had high oxygen of 0.45 0.46 mass\%, which were almost constant with changing the sintering temperature. The tensile properties of high strength and low elongation in the $\mathrm{HDH}$ powder specimen was considered to be caused by this high oxygen content ${ }^{1-3)}$. As for the gas-atomized powder specimen, the oxygen contentwas influenced by the sintering temperature. The sintering temperature showed the minimum oxygen

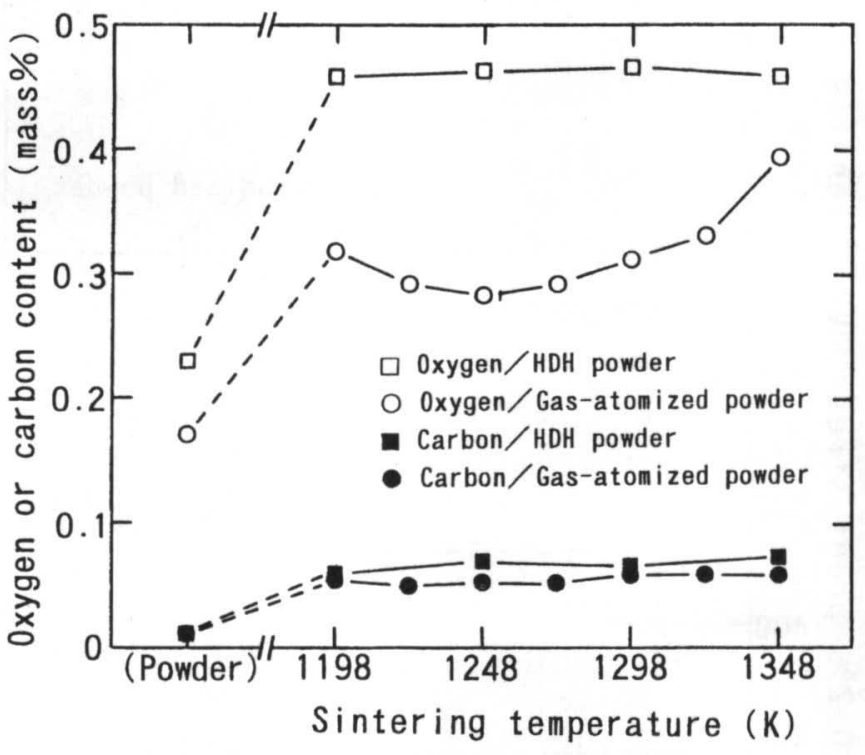

Fig.6 Relationship between carbon and oxygen contents and sintering temperature. content $(0.28$ mass $\%)$ was $1248 \mathrm{~K}$, and at this temperature the elongation became the maximum $(\sim 20 \%)$.

The increase in oxygen content of the sintered specimens from that of the original powder is considered to be caused by trapping from organic binder or debinding atomosphere. It is difficult to explain precisely the cause of the difference in oxidation behaviours of the specimens of both powders in Fig.6.

However, the increase in oxygen content of the gasatomized powder specimen sintered at more than $1323 \mathrm{~K}$, as shown in Fig.6 ( 0.33 mass\%<), is due to the reaction to alumina powder embedding the specimenat sintering ${ }^{4.5)}$. In other words, the influence of this alumina powder on the sintered specimen was considered to be disregarded when sintering temperature was less than $1298 \mathrm{~K}$.

Fig.7 shows the SEM photographs of fracture surface after tensile test of the HDH powder specimens at various sintering temperatures. Since the specimen sintered at $1198 \mathrm{~K}$ had low density of $82.5 \%$, a lot of large irregularshaped pores were observed on its fracture surface. Moreover,the shape of original powder still remained ${ }^{6}$. These surface condition fitted in low tensile properties as shown in Fig.5. Rising the sintering temperature to $1298 \mathrm{~K}$ (relative density is $92.5 \%$ ), the shape of pores changed to spherical, and dimple patterns peculiar to ductile fracture were observed. When sintering temperature was $1348 \mathrm{~K}$ (relative density is $94.5 \%$ ), cleavage planes suggesting brittle fracture were observed on the fracture surface.

Fig. 8 shows the SEM phtographs of fracture surfaces of the gas-atomized powder specimens. As a whole, the surface condition was similar to that of the $\mathrm{HDH}$ powder specimen sintered at the same temperature. However, fracture facets of the gas-atomized powder specimens were smaller than those of HDH powder specimens. This fact is considered to be due to the difference of original powder size.
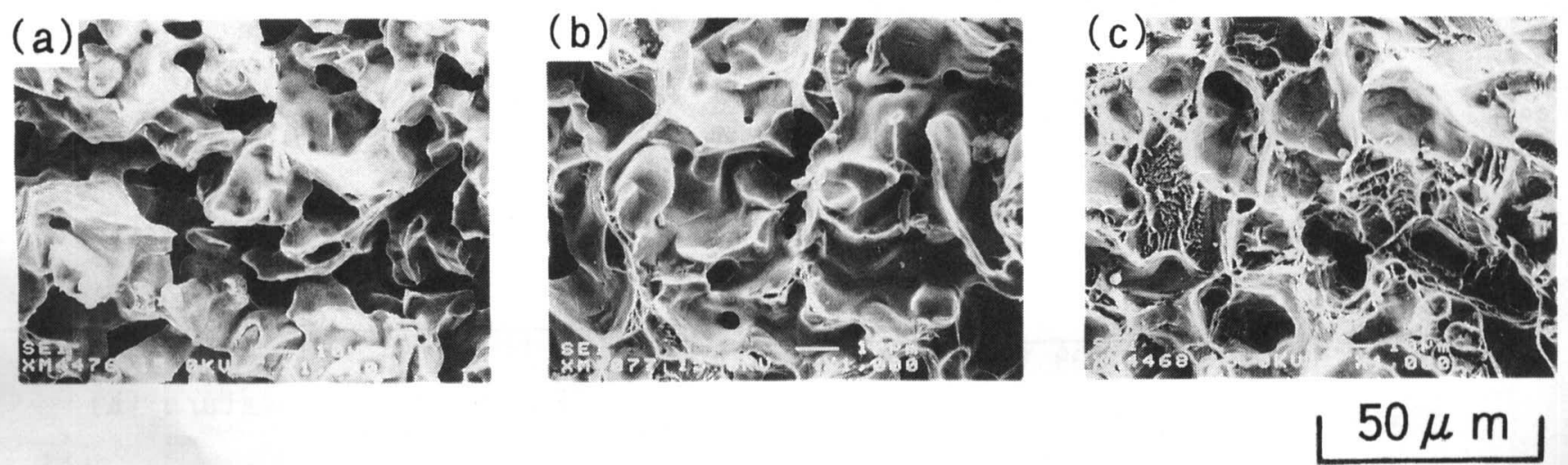

Fig.7 SEM images of fracture surfaces of $\mathrm{HDH}$ powder specimens. Sintering temperature: (a) $1198 \mathrm{~K}$ (b) $1298 \mathrm{~K}$ (c) $1348 \mathrm{~K}$ 

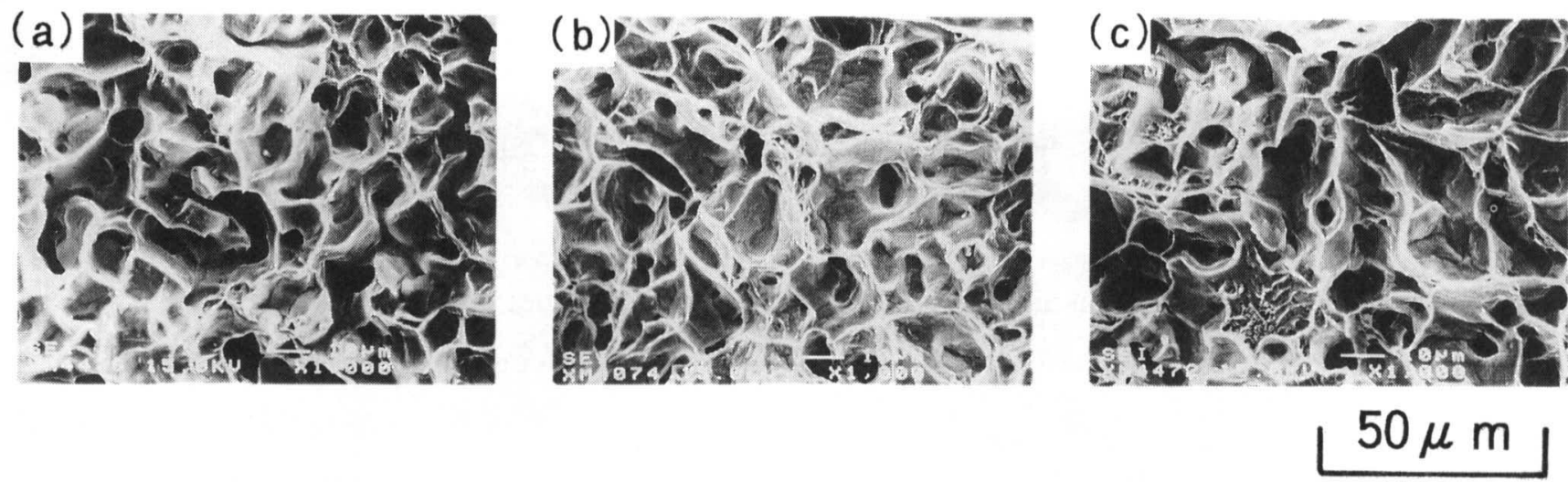

Fig.8 SEM images of fracture surfaces of gas-atomized powder specimens. Sintering temperature: (a) $1198 \mathrm{~K}$ (b) $1298 \mathrm{~K}$ (c) $1348 \mathrm{~K}$

\section{Conclusions}

To prepare pure-Ti compacts by MIM process, the sintering was performed at the temperature range between $1198 \mathrm{~K}$ and $1348 \mathrm{~K}$. The following results were obtained from the investivation in properties of the sintered compacts.

(1) When $\mathrm{HDH}$ powder (average particle size: $23 \mu \mathrm{m}$ ) was used as the material, the compact sintered at more than $1298 \mathrm{~K}$ showed high tensile strength $(630 \mathrm{MPa}<)$ in spite of low relative density (92.5 94.5\%).

(2) When gas-atomized powder (average particle size: $15 \mu \mathrm{m}$ ) was used, the sintered compact showed high density ( $95 \%)$ and high elongation (15 20\%) at low sintering temperature range $(1248 \mathrm{~K} \sim 1298 \mathrm{~K})$.

\section{References}

1) W.L.Finlay and J.A.Snyder: "Effects of Three Interstitial Solutes (Nitrogen, Oxygen, and Carbon) on the Mechanical Properties of High-purity, Alpha Titanium",
Trans. AIME, 188(1951)277-286.

2) R.I.Jaffee, H.R.Ogden and D.J.Maykuth: "Alloys of Titanium with Carbon, Oxygen, and Nitrogen", Trans. AIME, 188(1951)1261-1266.

3) K.Majima, T.Isono and K.Shoji: "Effect of Oxygen on Mechanical Properties of Sintered Titanium", J. Jap. Soc. Powder and Powder Metallurgy, 33(1986)28-33.

4) T.Kono, A.Horata and T.Kondo: "Development of Titanium and Titanium Alloy by Metal Injection Molding", J. Jap. Soc. Powder and Powder Metallurgy, 44(1997)985-992.

5) T.Ieki, K.Kato, A.Matsumoto, T Masui and K Ando: "Tensile Properties of Ti Sintered Compacts by Metal Injection Molding", J. Jap. Soc. Powder and Powder Metallurgy, 44(1997)448-452.

6) K.Majima, T.Hirata and K.Shoji: "Effects of Purity of Titanium Powder and Porosity on Static Tensile Properties of Sintered Titanium Specimens", J. Jap. Inst. Metals, 51(1987)1194-1200. 